\title{
Evaluation of Degradation Efficiency of 2'-Ethylhexyl 4-(Dimethylamino)Benzoate under the Influence of Oxidizing Agents
}

\author{
Waldemar Studziński ${ }^{*}$, Alicja Gackowska ${ }^{1}$ \\ 1 Faculty of Chemical Technology and Engineering, UTP University of Science and Technology, Seminaryjna 3, \\ 85-326 Bydgoszcz, Poland \\ * Cotrresponding author's e-mail: waldemar.studzinski@utp.edu.pl
}

\begin{abstract}
The aim of the studies was to evaluate the effect of oxidizing agents on the degradation of 2-ethylhexyl 4-(dimethylamino)benzoate (ODPABA). The oxidation reaction was carried out in the presence of oxidizing agents used for disinfection of water and treatment of sewage containing organic pollutants. Oxidants, such as: sodium hypochlorite, hydrogen peroxide or ozone with UV radiation were applied. ODPABA degradation and analysis of products were performed using a gas chromatograph coupled with mass spectrometry detector. The use of sodium hypochlorite and UV radiation proved to be the most effective solutions. As a result, halogenoorganic products are formed. It is likely that the resulting by-products can be more toxic than the initial substrate. In the case of ozone and hydrogen peroxide, it was shown that these agents are characterized by weaker oxidative activity and therefore, fewer metabolites are formed.
\end{abstract}

Keywords: UV filters, OD-PABA, sewage, environment pollution, degradation

\section{INTRODUCTION}

UV filters are chemical compounds the main purpose of which is to protect the skin against the negative effects of UV radiation [Dias-Cruz et al., 2008]. UV filters are widely used in personal care products, i.e.: lipsticks, body lotions, hairsprays and also as an additive preventing the degradation of polymers and pigments [Negreira et al. 2008, Gackowska et al. 2014]. Due to the wide use of UV-filters in various products, special attention was paid to their occurrence and impact on the environment [Dirtu et al. 2012]. According to the literature data, ultraviolet filters can infiltrate into environment from direct and indirect sources [Dias-Cruz et al. 2012]. The direct sources include the phenomena associated with the release of substances from the surface of the skin, e.g. during washing, bathing or swimming [la Farré et al. 2008]. Particularly large consumption of UV-filters is observed during the summer time, which is caused by increased skin exposure to solar radiation [Zuloaga et al. 2012]. Indirect sources of pollution are wastewater from households, which arise as a result of washing or rinsing but also from municipal and industrial wastes [Santos et al. 2013].

The stability of filters under the influence of external agents is a very important aspect for the producers of sunscreens, because it is connected with the loss of photo-protective properties of product [Dias-Cruz et al. 2008]. The durability of UV filters is also an important problem for environment protection. It has been shown that sunscreens have the ability to accumulate in different matrices, which can result in the formation of undesirable products under the influence of external agents [Negreira et al. 2008]. Due to their accumulation in the environment and lack of constant monitoring, they are considered as new pollutants - "emerging contaminations (ECs)" [Gomez et al. 2012]. In order to learn about the processes of conversions that they can undergo in the aquatic environment, studies on the impact of various environmental agents on their behaviour are conducted. These studies are very important, because 
Giakos et al. [2007] have shown that UV filters in the aquatic environment can react with components of water matrix such as: dissolved organic matter, chlorides or nitrates. Stability can also be influenced by, for example: oxygen, peroxide radicals, hydroxyl groups, etc. [Santos et al.,2013].

One of the commonly used UV filters is 2'-ethylhexyl 4-(dimethylamino) benzoate (ODPABA). Among the current ODPABA durability studies, the effect of radiation has been examined, noting the reduction of the protective properties of the UV filter [Serpone et al. 2002]. Moreover, the effect of matrix on ODPABA conversion was checked. The analysis of filter was carried out in three different matrices: sea, distilled and pool water. The studies show that by-products, including chlorine derivatives, have been detected in seawater and pool water [Santos et al. 2013; Dias-Cruz et al. 2008]. It was found that ODPABA readily reacted with disinfectants and the organic matter present in water mainly from pools [Santos et al. 2013; Dias-Cruz et al. 2008]. For 2 '-ethylhexyl 4-(dimethylamino) benzoate, this process involves substituting one hydrogen atom in the aromatic ring with chlorine or bromine. It was found that the rate of filter decomposition and the amount of halogen derivative by-products also depends on the $\mathrm{pH}$ of the system [Negreira et al., 2008]. Due to the fact that ODPABA and other UV filters can undergo conversions in the environment, as a result of which by-products with much higher toxicity than the substrate can be formed, a trend of actions leading to the improvement of wastewater treatment methods by eliminating the radiation-protective compounds is observed. The aim of these activities is to eliminate the pollutants which, due to their properties (lipophilicity, poor biodegradability), after applying traditional methods of wastewater treatment, do not degrade and percolate into surface waters together with the treated wastewater. A promising solution can be advanced oxidation processes AOPs [Krzemińska et al. 2015; Kasih 2017].

The aim of the study was to evaluate the efficiency of degradation of 2'-ethylhexyl 4-(dimethylamino) benzoate in an aqueous matrix under the influence of oxidizing agents such as hydrogen peroxide, ozone, sodium hypochlorite in the presence of UV radiation. An attempt was also made to identify the by-products formed.

\section{MATERIALS AND METHODS}

Chemical filter 2-ethylhexyl 4-(dimethylamino)benzoate (ODPABA) 99\%, CAS 21245-02-3, from Sigma Aldrich was used in our studies. Hydrogen peroxide $\left(\mathrm{H}_{2} \mathrm{O}_{2} 30 \%\right)$ and sodium chlorate (I) $(\mathrm{NaOCl} 100 \mathrm{~g} / \mathrm{L}$ of free chlorine) purchased from $\mathrm{POCH}$ company were selected as the oxidizing agents. Another agent was ozone, which was produced by the DRP-30.7 VW generator, at the flow of $4 \mu \mathrm{l} / \mathrm{min}$.

Aqueous solutions of $0.36 \mathrm{mM}$ ODPABA were introduced into the Heraeus reactor and individual oxidants were added in the proportions given in Table 1 . The studies on the additive effect of UV radiation were carried out using a medium-pressure mercury lamp with a range of 200-600 nm. The mercury lamp was placed in a water jacket to maintain a constant reaction temperature of $20^{\circ} \mathrm{C}$. The reactor was placed on a magnetic stirrer $(200 \mathrm{rpm})$ to ensure uniform distribution of reagents in the solution.

The samples for qualitative and quantitative analysis were collected at various time intervals. From each test system, $100 \mathrm{ml}$ of solution, after a specified time, was sampled and extracted with $20 \mathrm{ml}$ of dichloromethane. The obtained extract was dried with anhydrous sodium sulfate and then concentrated in a vacuum evaporator to the volume of $1 \mathrm{ml}$. The change of ODPABA concentration in time under the influence of oxidizing agents and UV radiation as well as identification of degradation products was carried out using 5890 HEWLETT PACKARD gas chromatograph equipped with a MS detector and the ZB-5MS column $(0.25 \mathrm{~mm} \times 30 \mathrm{~m} \times 0.25 \mu \mathrm{m})$. Temperature program was as follows: $80^{\circ} \mathrm{C}-10^{\circ} \mathrm{C} / 1 \mathrm{~min}$ $-260^{\circ} \mathrm{C}-5^{\circ} \mathrm{C} / 1 \mathrm{~min}-300^{\circ} \mathrm{C} / 2 \mathrm{~min}$. The injection volume was $1 \mu$ l.

Table 1. The reaction conditions and substrate proportions used in this study

\begin{tabular}{|c|c|c|c|c|c|}
\hline Reagents & OD-PABA [mM] & $\mathrm{H}_{2} \mathrm{O}_{2}[\mathrm{mM}]$ & $\mathrm{NaOCl}[\mathrm{mM}]$ & $\mathrm{O}_{3}[\mathrm{mM}]$ & UV [W] \\
\hline ODPABA/UV & 0.36 & - & - & - & 150 \\
\hline ODPABA/NaOCI/UV & 0.36 & - & 10 & - & 150 \\
\hline ODPABA/ $\mathrm{H}_{2} \mathrm{O}_{2} / \mathrm{UV}$ & 0.36 & 10 & - & - & 150 \\
\hline ODPABA/O $/$ /UV & 0.36 & - & - & 10 & 150 \\
\hline
\end{tabular}




\section{RESULTS AND DISCUSSION}

On the basis of our studies, it was found that ODPABA was unstable under the influence of oxidizing agents in the presence of UV radiation (Fig. 1). The fastest ODPABA degradation was observed in the system with sodium hypochlorite in the presence of UV radiation. In this system, the half-life decomposition of the filter was observed after 60 minutes and after 180 minutes, the filter loss was about $90 \%$. In the case of $\mathrm{O}_{3} / \mathrm{UV}$ and $\mathrm{H}_{2} \mathrm{O}_{2} / \mathrm{UV}$ systems, the decomposition reactions ran more slowly than with $\mathrm{NaOCl} / \mathrm{UV}$. In both cases, the filter decomposition after $60 \mathrm{~min}-$ utes was found to be about $40 \%$, and after 180 minutes ODPABA was decomposed in $80 \%$. In the presence of sole UV radiation, ODPABA degradation proceeded the slowest. The results confirm that the application of advanced oxidation processes contributes to improving the efficiency of removing the filter from water matrix.

While studying the influence of oxidizing agents (hydrogen peroxide, sodium hypochlorite, ozone and UV radiation) on another filter 2'-ethylhexyl 4-methoxycinnamate (EHMC), a different dependence concerning the effectiveness of oxidizing agents was observed. The oxidation system with ozone and UV radiation was the most effective [Studziński et al. 2017]. By executing chlorination in swimming pools, Nakajima et al. [2009] revealed that ODPABA reacted with chlorine more rapidly than EHMC. The difference in reactivity is due to the presence of various substituents (methoxy and dimethylamino groups) in the benzene ring [Nakajima et al. 2009].

In search of the new methods for degradation of micro-pollutants with the use of oxidizing agents, scientists focus their attention on the method effectiveness [Przywara 2017; Kuśmierek et al. 2015]. During optimization of these methods, the efficiency of processes and the rate of pollutant degradation are checked [Lee et al. 2009; Hopkins et al. 2017]. There is little literature data concerning the conversions and further fate of pollutants after the oxidation process [Hopkins et al., 2017]. The products of conversions of micropollutants can cause secondary water contamination. Therefore, when assessing the method of ODPABA degradation of in water matrix, the analysis of metabolites formed in reaction with oxidizing agents was considered as well. The products of ODPABA conversions under the influence of $\mathrm{NaOCl} / \mathrm{UV}, \mathrm{H}_{2} \mathrm{O}_{2} / \mathrm{UV}$ and $\mathrm{O}_{3} / \mathrm{UV}$ oxidizing systems were presented in Figure 2.

As a result of sole ODPABA (1) water solution irradiation, three by-products were identified: 2'-ethylhexyl 4-aminobenzoate (3); 2-ethylhexan-1-ol (5); 2'-ethylhexyl 4-(methylamino) benzoate (8). The obtained results indicate that in presence of UV radiation, demethylation of the amino group takes place.

In the case of the ODPABA reaction with $\mathrm{Na}$ $\mathrm{OCl}$, it was found that ODPABA chlorine derivatives were present among the reaction products. The effect of sodium hypochlorite on the mechanism of ODPABA conversion has been discussed in our previous paper [Gackowska et al. 2016]. Under the influence of sodium hypochlorite in the presence of radiation, the following compounds were identified: 2-ethylhexan-1-ol (5); 2'-ethylhexyl 3-chloro-4-hydroxybenzoate (6); 2'-ethylhexyl dichloro-4-hydroxybenzoate (7); 2'-ethylhexyl-4-(methylamino) benzoate (8); 2'-ethylhexyl chloro-4-aminobenzoate (9); 2'-ethylhexyl chloro-4-(dimethylamino) benzoate (10); 2'-ethylhexyl chloro-4-(methylamino) benzoate (11);

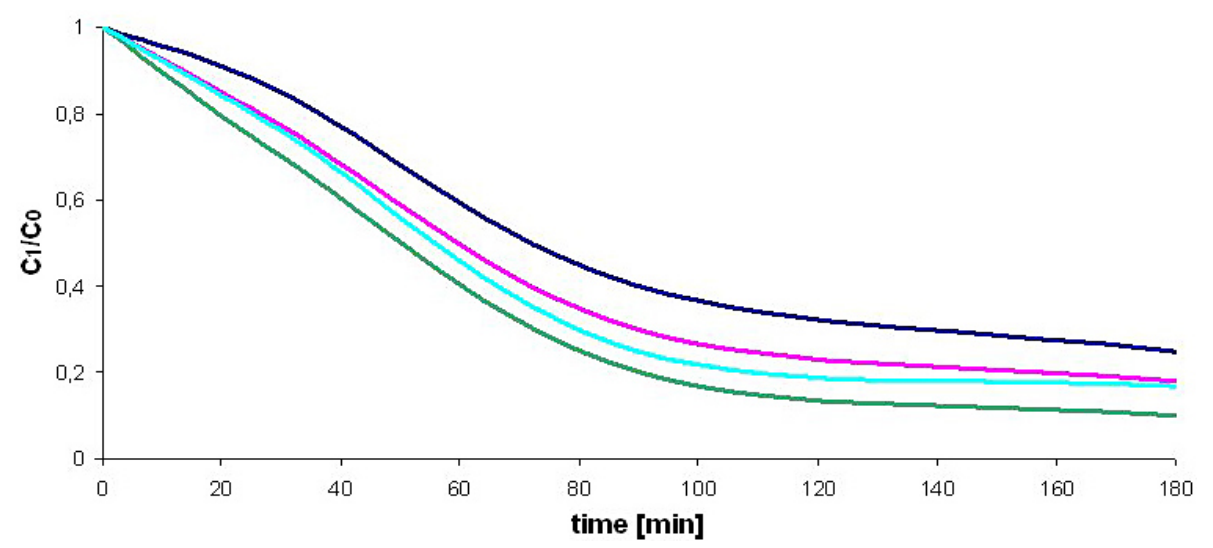

Fig. 1. ODPABA degradation under influence of the systems studied as a function of time: -ODPABA/UV; - ODPABA/ $\mathrm{H}_{2} \mathrm{O}_{2} / \mathrm{UV} ;-\mathrm{ODPABA} / \mathrm{O}_{3} / \mathrm{UV} ;-\mathrm{ODPABA} / \mathrm{NaOCl} / \mathrm{UV}$ 


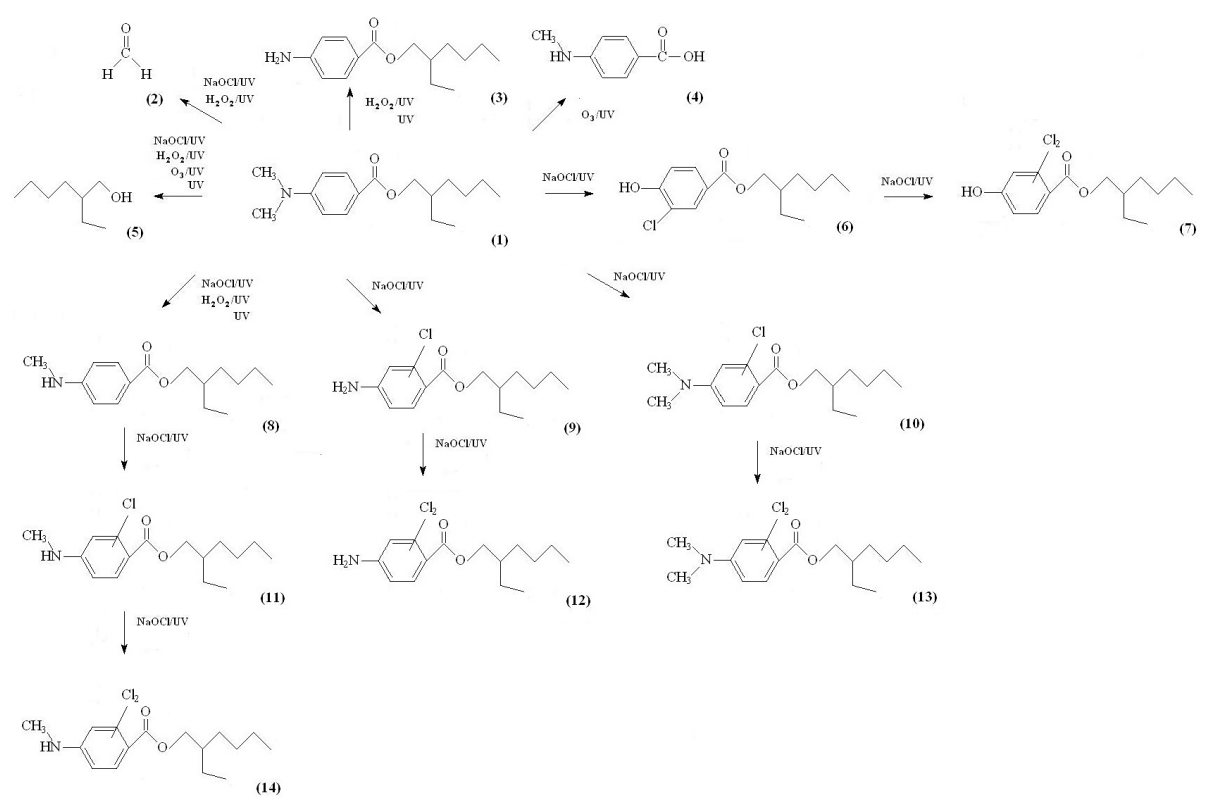

Fig. 2. ODPABA conversions under the influence of oxidizing agents

2'-ethylhexyl dichloro-4-aminobenzoate(12); 2 '-ethylhexyl dichloro-4-(dimethylamino) benzoate (13) 2'-ethylhexyl dichloro-4-(methylamino) benzoate (14). Similar results of ODPABA chlorination were obtained by Sakkas et al. [2003] and Nakajimo et al. [2009]. Formation of chloroorganic products in the processes of water disinfection under the influence of sodium hypochlorite is characteristic for many organic compounds. This type of reaction is particularly preferred by the compounds containing phenolic and/or amine groups in their structure [Bedner and MacCerhan 2006; Negreira et al. 2008].

Moreover, Studziński et al. [2017b] found that in the presence of oxidizing agents $(\mathrm{NaOCl}$ and $\mathrm{H}_{2} \mathrm{O}_{2}$ ) formaldehyde (2), which has toxic and carcinogenic properties, was formed as well. It should be noted that even a small concentration of this aldehyde $\left(<10^{-4} \mathrm{M}\right)$ can cause a DNA damage in human skin cells [Emri et al. 2004].

In the presence of peroxide or ozone and UV radiation, the ODPABA degradation process proceeds slower and significantly fewer by-products are formed. Under the influence of $\mathrm{H}_{2} \mathrm{O}_{2} / \mathrm{UV}$ system, 2'-ethylhexyl 4-aminobenzoate (3); 2-ethylhexan-1-ol (5); 2'-ethylhexyl 4-(methylamino) benzoate (8) were identified among the reaction products by GC-MS method (Fig. 3).

The solution generating the smallest amount of products in the ODPABA oxidation process is the ozonation in the presence of UV radiation. The reaction products identified in ODPABA $/ \mathrm{O}_{3} /$ UV system were 4-(methylamino) benzoic acid (4) and 2-ethylhexan-1-ol (5) (Fig. 4).

Increased awareness of the harmful effects of chloroorganic products used for disinfection of wa-

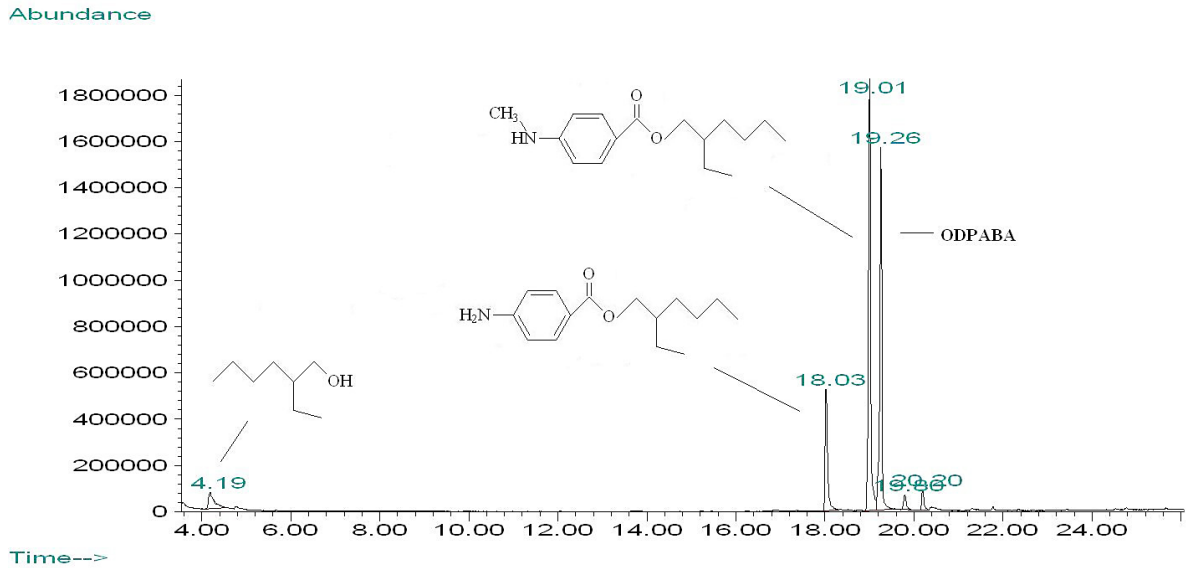

Fig. 3. Chromatogram of ODPABA/ $\mathrm{H}_{2} \mathrm{O}_{2} \mathrm{UV}$ system after 60 minutes 


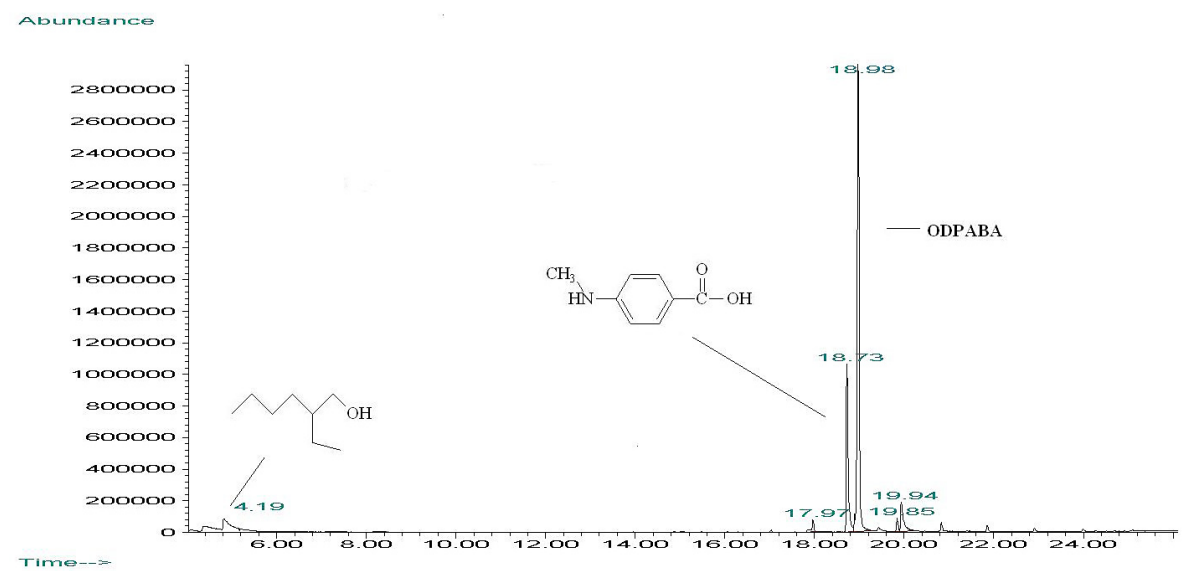

Fig. 4. Chromatogram of ODPABA/ $\mathrm{O}_{3} / \mathrm{UV}$ system after 60 minutes

ter on living organisms contributed to the development of alternative solutions consisting in limiting the use of chlorine-based disinfectants. Due to the high potential of chemical oxidation and lack of trihalomethane (THM) formation, ozone is applied [Lee et al. 2009). However, under actual conditions, the effectiveness of ozone can be much lower because it acts non-selectively and competitive processes with other pollutants can proceed [Li et al. 2007]. Considering that ozone rapidly reacts in the oxidation process and the use of high doses is needed, studies are carried out to optimize the ozone disinfection process using sequential systems with chlorine (ozone/chlorine) [Lee et al., 2009] and UV radiation (ozone/ UV radiation) [Gago-Ferrero et al., 2013]. The results obtained confirm the observations described by Lee et al. [2009]. It was found that ODPABA was effectively degraded by ozone and the amount of identified products was lower than in the case of $\mathrm{NaOCl}$ application.

Regardless of the type of oxidizing agent used, in the first stage of ODPABA degradation, the amine group is demethylated and then disintegration into lower molecular weight compounds occurs. The resulting products are at trace levels and are characterized by similar physicochemical properties. Their separation and isolation is arduous; hence, the assessment of a particular product on the environment is difficult. According to Nakajima et al. [2009] during disinfecting water with sodium hypochlorite, ODPABA forms mutagenic products. Therefore, according to the authors, development of research to assess the toxicity of all ODPABA conversion products can contribute not only to broadening of the knowledge about their properties, but will also be a valuable source of information in the context of assessment of the quality of water resources.

\section{CONCLUSIONS}

It was found that ODPABA was unstable under the influence of oxidizing agents, such as sodium hypochlorite, hydrogen peroxide and ozone. The process conducted with the participation of oxidizing agents in the presence of UV radiation accelerates the degradation of UV filter.

Our studies have shown that in each variant, the products which were formed could lead to secondary water pollution. The most effective solution was the use of sodium hypochlorite and UV radiation. However, this solution generated a large number of halogenorganic metabolites. It is likely that the resulting by-products can be more toxic than the initial substrate.

In the case of ozone and hydrogen peroxide, it has been shown that these agents exhibit weaker oxidative activity and cause formation of a smaller number of metabolites. The application of suitable oxidation processes can contribute to the degradation of micro-pollutants, and thus to an improvement of the water quality.

\section{REFERENCES}

1. Bedner M. and MacCrehan W.A. 2006. Transformation of acetaminophen by chlorination produces the toxicants 1,4-benzoquinone and N-acetyl-pbenzoquinone imine. Environ. Sci. Technol., 40(2), 516-522.

2. Díaz-Cruz M.S., Gago-Ferrero P., Liorca M., Barceló D. 2012. Analysis of UV filters in tap water and other clean waters in Spain. Anal. Bioanal. Chem., 402(7), 2325-2333.

3. Díaz-Cruz M.S., Liorca M., Barceló D. 2008. Organic UV filters and their photodegradates, metabolites and disinfection by-products in the aquat- 
ics environment. Trends Analyt. Chem., 27 (10), 873-887.

4. Dirtu A.C., Ede N., Malarvannan G., Ionas A.C., Covaci A. 2012. Analytical methods for selected emerging contaminants in human matrices - a review. Anal. Bioanal. Chem., 404(9), 2555-2581.

5. Emri G., Schaefer D., Held B. 2004. Low concentrations of formaldehyde induce DNA damage and delay DNA repair after UV irradiation in human skin cells. Exp. Dermatol., 13(5), 305-315.

6. Farré La Marinenel., Pérez S., Kantiani L., Barceló D. 2008. Fate and toxicity of emerging pollutants, their metabolites and transformation products in the aquatic environment. Trends Analyt. Chem., 27(11), 991-1007.

7. Gackowska A., Przybyłek M., Studziński W., Gaca J. 2014. Experimental and theoretical studies on the photodegradation of 2-ethylhexyl 4-methoxycinnamate in the presence of reactive oxygen and chlorine species. Cent. Eur. J. of Chem., 12(5), 612-623.

8. Gackowska A., Studziński W., Gaca J. 2016. Effect of sodium hypochlorite on conversions of octyldimethyl- para -aminobenzoic acid. Desalin. Water Treat., 57(3), 1429-1435.

9. Gago-Ferrero P., Demeestere K., Silvia Díaz-Cruz M., Barceló D. 2013. Ozonation and peroxone oxidation of benzophenone-3 in water: effect of operational parameters and identification of intermediate products. Sci. Total. Environ. 443, 209-217.

10. Giokas D.L., Salvador A., Chisvert A. 2007. UV filters: From sunscreens to human body and the environment. Trends Anal. Chem., 26(5), 360-374.

11. Gomez E., Bachelot M., Boillot C., Munaron D., Chiron S., Casellas C., Fenet H. 2012. Bioconcentration of two pharmaceuticals (benzodiazepines) and two personal care products (UV filters) in marine mussels (Mytilus galloprovincialis) under controlled laboratory conditions. Environ Sci Pollut Res 19(7), 2561-2569.

12. Hopkins Z.R., Snowberger S., Blaney L. 2017. Ozonation of the oxybenzone, octinoxate, and octocrylene UV-filters: Reaction kinetics, absorbance characteristics, and transformation products. J Hazard Mater., 338, 23-32.

13. Kasih T.P. 2017. Investigation of the non-thermal plasma-based advanced oxidation process for removal of organic contaminants in azo dyes solution. J. Ecol. Eng. 18(2), 1-6.

14. Krzemińska D., Neczaj E., Borowski G. 2015. Advanced oxidation processes for food industrial wastewater decontamination. J. Ecol. Eng., 16(2), 61-71.

15. Kuśmierek K., Świątkowski A., Dąbek L. 2015. Oxidative degradation of 2-chlorophenol by persulfate. J. Ecol. Eng. 16(3), 115-123.

16. Lee J., Ha K-T., Zoh K-D. 2009. Characteristics of trihalomethane (THM) production and associated health risk assessment in swimming pool waters treated with different disinfection methods. Sci Total Environ. 407(6), 1990-1997.

17. Li W.H., Ma Y.M., Guo C.S., Hu W., Liu K.M., Wang Y.Q., Zhu T. 2007. Occurrence and behavior of four ofthe most used sunscreen UV filters in a wastewater reclamation plant. Water Res., 41(15), 3506-3512.

18. Nakajima M., T. Kawakami T., Niino T., Takahashi Y. and Onodera S. 2009. Aquatic fate of sunscreen agents octyl-4-methoxycinnamate and octyl-4-dimethylaminobenzoate in model swimming pools and the mutagenic assays of their chlorination byproducts. J. Health Sci., 55(3), 363-372.

19. Negreira N., Canosa P., Rodriguez I., Rubi R., Cele R. 2008. Study of some UV filters stability in chlorinated water and identification of halogenated byproducts by gas chromatography-mass spectrometry, J. Chromatogr. A 1178(1-2) 208-214.

20. Przywara L., 2017. Alternative treatment strategy for different streams of tannery wastewater. J. Ecol. Eng. 18(4), 160-168.

21. Sakkas V.A., Giokas D.A., Lambropoulou D.A. and Albanis T.A., 2003. Aqueous photolysis of the sunscreen agent octyl-dimethyl-p-aminobenzoic acid Formation of disinfection byproducts in chlorinated swimming pool water, J. Chromatogr. A, 1016(2), 211-222.

22. Santos A. Joel M., Crista D.M.A., Miranda M.S., Almeida I.F., Sousa E Silva J.P., Costa P. C., Amaral M.H., Lobão A.L., Sousa Lobo J.M., Esteves Da Silva J.C.G. 2013. Degradation of UV filters 2-ethylhexyl-4-methoxycinnamate and 4-tert-butyl-4'-methoxydibenzoylmethane in chlorinated water. Csiro Publishing, 36(10), 1319-1326.

23. Serpone N, Salinaro A, Emeline AV, Horikoshi S, Hidaka H., Zhao J. 2002. An in vitro systematic spectroscopic examination of the photostabilities of a random set of commercial sunscreen lotions and their chemical UVB/UVA active agents, Photochem Photobiol Sci., 1(12), 970-981.

24. Studziński W., Gackowska A. 2017. Comparison of methods for ethylhexyl 4-methoxycinnamate acid ester oxidation in water medium. J. Ecol. Eng, 18(4), 204-210.

25. Studziński W., Gackowska A., Przybyłek M., Gaca J. 2017b. Studies on the formation of formaldehyde during 2-ethylhexyl 4-(dimethylamino)benzoate demethylation in the presence of reactive oxygen and chlorine species. Environ. Sci. Pollut. Res, 24(9), 8049-8061.

26. Zuloaga O., Navarro P., Bizkarguena E., Iparraguirre A., Vallejo A., Olivares M., Prieto A. 2012. Overview of extraction, clean-up and detection techniques for the determination of organic pollutants in sewage sluge: A review. Anal. Chim. Acta, 736, 7-29. 